\title{
O mito da leniência fiscal no pensamento econômico desenvolvimentista *
}

\author{
Marcelo Curado \\ Virginia Laura Fernández.***
}

\begin{abstract}
Resumo
O objetivo deste artigo é analisar a "tese de leniência fiscal" do desenvolvimentismo apresentada, entre outros, por Franco (1996, 2004, 2005). De acordo com esta tese, "gerações de desenvolvimentistas" propuseram um modelo de desenvolvimento no qual os desequilíbrios fiscais não eram apenas aceitáveis, mas sim parte crucial do financiamento dos investimentos. $\mathrm{O}$ artigo analisa duas gerações de desenvolvimentistas: a original, a partir das contribuições acadêmicas de seus expoentes intelectuais, Roberto Simonsen, Roberto Campos e Celso Furtado, e a nova geração formada pelas contribuições do novo e do social desenvolvimentismos. A revisão da literatura permite concluir que não há suporte para a tese da leniência fiscal. Os desenvolvimentistas originais sugeriram outros mecanismos para financiar os investimentos, como por exemplo, empréstimos do exterior ou ainda a elevação dos tributos. Outro resultado é que a leniência fiscal não faz parte da agenda do novo e do social desenvolvimentismos, já que são comprometidos com o equilíbrio fiscal.
\end{abstract}

Palavras-chave: Pensamento econômico brasileiro: Desenvolvimentismo; Novo e social desenvolvimentismos; Política fiscal; Leniência fiscal.

\begin{abstract}
The myth of fiscal leniency in developmentalist economic thought

The aim of this paper is to analyze the "fiscal leniency thesis" of developmentalism presented, among others, by Franco $(1996,2004,2005)$. According to this thesis, "generations of developmentalists" proposed a development model in which the fiscal imbalances were not only acceptable but a crucial part of investment finance. The paper examines two generations of developmentalists: the original, from the academic contributions of its intellectual exponents, Roberto Simonsen, Roberto Campos and Celso Furtado, and the new generation formed by the contributions of new and social developmentalism. The literature review shows that there is no support for the theory of fiscal leniency. Original developmentalists suggested other mechanisms to finance investments, such as foreign loans or raising taxes. An additional result is that fiscal leniency is not part of the new and social developmentalism agenda, since they are committed to the fiscal balance.
\end{abstract}

Keywords: Brazilian economic thought; Developmentalism; New and social developmentalism; Fiscal policy; Fiscal leniency.

JEL B2, B29, E62.

* Artigo recebido em 28 de fevereiro de 2016 e aprovado em 1 de outubro de 2016. Os autores agradecem aos comentários feitos pelos pareceristas anônimos, eximindo-os das falhas remanescentes.

** Professor do Departamento de Economia e do Programa de Pós-Graduação em Desenvolvimento Econômico da Universidade Federal do Paraná (UFPR), Curitiba, PR, Brasil. O autor agradece ao Conselho Nacional de Desenvolvimento Científico e Tecnológico (CNPq) pelo apoio financeiro. E-mail: curado@ufpr.br.

**** Professora da Facultad Ciencia Política y Relaciones Internacionales da Universidad Nacional de Rosario (Argentina) e do Departamento de Economia da UFPR, Curitiba, PR, Brasil. E-mail: virginialaurafernandez@yahoo.com.ar. 


\section{Introdução}

A associação entre desenvolvimentismo, desequilíbrio fiscal e leniência no trato com a inflação é recorrente nas discussões econômicas brasileiras. Economistas renomados e que têm grande exposição na mídia, tal como o ex-presidente do Banco Central, Gustavo Franco, argumentam que "várias gerações de desenvolvimentistas" tiveram uma postura complacente com a persistência de desequilíbrios fiscais e a aceleração da inflação. A tese da "leniência fiscal" apresentada por Franco (1996, 2004 e 2005) vai além e propõe que o desequilíbrio fiscal era parte essencial do modelo de financiamento dos investimentos no processo de substituição de importações.

Uma das características mais marcantes da interpretação de Franco sobre o significado do desenvolvimentismo, que ele batiza de "inflacionismo", é a não separação entre o plano das ideias e a ação concreta da política econômica. "A ênfase na industrialização raramente conheceu circunstâncias atenuantes nos anos em que reinaram Prebish, Furtado e os desenvolvimentistas. O imaginário do desenvolvimento brasileiro registra, como ícones desses anos dourados, a figura sorridente e confiante de JK, a construção de Brasília [...] e, por fim, o enunciado básico do nosso futuro, onde se explicava como viver 50 anos em cinco, o Plano de Metas" (Franco, 2004, p. 5)

A passagem selecionada é um exemplo de como a interpretação de Franco sobre o desenvolvimentismo não estabelece a necessária distinção entre o plano das ideias e o da ação concreta derivada da política econômica. Ainda que estes planos não sejam totalmente dissociáveis (Fonseca, 2004), a análise da perspectiva da história do pensamento não pode desconsiderar que o debate produzido no campo das ideais está longe de ter correlação direta com as ações da política econômica. Em outras palavras, ainda que tenham exercido influência, as discussões estabelecidas pelos expoentes intelectuais desenvolvimentistas não podem ser confundidas com os rumos adotados pelos distintos governos ao longo do período.

Apesar de muito difundida, especialmente na grande mídia, a tese da leniência com os desequilíbrios fiscais e com a inflação no pensamento desenvolvimentista está longe de ser consensual. Bielschowsky (1988), por exemplo, não apresenta o financiamento dos investimentos através de desequilíbrios fiscais como uma característica do desenvolvimentismo. Fonseca (2013) também não argumenta neste sentido. Outros autores, como Bresser-Pereira tiveram o cuidado de promover a necessária distinção entre o plano das ideias e o da ação concreta da política econômica. De acordo com o autor: "Os notáveis economistas, como Furtado, Prebisch e Rangel, formuladores da estratégia desenvolvimentista, eram keynesianos e, na promoção do desenvolvimento, consideravam a administração da demanda agregada como uma ferramenta importante. Contudo, nunca defenderam 
o populismo econômico dos déficits crônicos" (Bresser-Pereira, 2006, p. 15, grifo nosso).

O presente trabalho pretende contribuir para a discussão na área, especificamente para a compreensão da "questão fiscal" no pensamento econômico desenvolvimentista desde suas origens até o debate mais recente promovido a partir da elaboração e difusão do novo e do social desenvolvimentismos. De modo mais preciso, o artigo investiga se estas duas gerações de trabalhos podem ser consideradas lenientes no trato do desequilíbrio fiscal. Duas questões norteiam a pesquisa: (i) Os expoentes intelectuais do desenvolvimentismo original foram defensores do uso de déficits públicos como instrumento para financiamento dos investimentos no processo de substituição de importações? E (ii) O novo e o social desenvolvimentismos advogam a favor do uso de déficits públicos como mecanismo de promoção do crescimento e mudança da estrutura produtiva, ou seja, são lenientes no trato da questão fiscal? ${ }^{1}$

Para responder estas indagações, o artigo promove uma revisão das contribuições de expoentes intelectuais do desenvolvimentismo nos dois momentos históricos selecionados. O primeiro, refere-se ao momento batizado por Bielschowsky (1988) como "o ciclo ideológico do desenvolvimentismo"2 e que teve em Roberto Simonsen, Roberto Campos e Celso Furtado seus expoentes intelectuais. O segundo, promove uma discussão da questão fiscal no contexto de surgimento e difusão do novo e do social desenvolvimentismos no Brasil a partir da segunda metade da década passada.

O trabalho pretende contribuir para os esforços recentemente empreendidos por diversos pesquisadores da história do pensamento econômico brasileiro em reinterpretar o significado das ideias econômicas oriundas do desenvolvimentismo original, tais como, por exemplo, as contribuições ao debate realizadas por BresserPereira (2006), Curi e Cunha (2011), Mollo e Fonseca (2013), Fonseca (2013) e Curado (2013) e Curado e Cavalieri (2015).

É importante salientar que o trabalho irá, dentro do possível, concentrar a análise no campo da evolução das ideias econômicas. Além dos limites de espaço próprios de um artigo acadêmico, justifica-se esta opção pelo fato de que no plano da história econômica é amplamente reconhecido que a associação entre os governos desenvolvimentistas e a leniência com desequilíbrios fiscais não encontra respaldo. Bastos (2008), Fonseca e Bastos (2011), Fonseca (2011) e Mollo e Fonseca (2013)

(1) É importante sublinhar que o trabalho não irá analisar a viabilidade ou a adequação histórica das propostas desenvolvimentistas para o financiamento dos investimentos. A discussão será restrita à questão do uso de desequilíbrios fiscais para o financiamento dos investimentos industriais.

(2) De acordo com Bielschowsky (1988) o auge do ciclo ideológico do desenvolvimento ocorreu entre 1945 e 1964. A revisão da literatura irá concentrar seus esforços nas discussões realizadas neste período. 
apresentam evidências históricas que permitem refutar a tese de que os governos desenvolvimentistas entre 1930 e 1964 podem ser homogeneamente classificados como lenientes no campo fiscal. A análise histórica demonstra que existem diferenças substantivas no trato da questão fiscal, por exemplo, entre o segundo governo Vargas (1951-1954) e o governo Juscelino (1956-1960).

Após esta introdução, apresenta-se uma breve qualificação sobre o significado do desenvolvimentismo em seu formato original e sua evolução posterior no novo e social desenvolvimentismos. A seção é necessária para dar maior precisão às discussões posteriores, apesar da vasta literatura existente sobre o tema. A segunda seção é dedicada à análise da questão fiscal nos expoentes intelectuais do desenvolvimentismo original. A terceira seção promove o debate para as correntes contemporâneas do desenvolvimento. Finalmente, apresentam-se as considerações finais do trabalho.

\section{Desenvolvimentismo, novo e social desenvolvimentismos: conceitos preliminares}

Esta seção cumpre o papel de apresentar, ainda que brevemente, o significado do desenvolvimentismo original e das construções mais recentes, o novo e o social desenvolvimentismos. A existência de vasta literatura sobre o significado do desenvolvimentismo original e o foco deste trabalho tornam desnecessária a reconstrução detalhada do conceito $^{3}$. As definições de Bielschowsky (1988) e Fonseca (2013) sobre o tema são apresentadas como sínteses destas discussões e norteiam o presente trabalho.

Bielschowsky (1988) propõe que o desenvolvimentismo original deve ser compreendido como "projeto de superação do subdesenvolvimento através da industrialização integral, por meio do planejamento e da intervenção direta do Estado na atividade econômica" (Bielschowsky, 1988, p. 7). O projeto econômico desenvolvimentista era composto por quatro elementos fundamentais:

a) a industrialização integral é a via de superação da pobreza e do subdesenvolvimento; b) não há meios de alcançar a industrialização eficiente e racional no Brasil através das forças espontâneas de mercado; por isso, é necessário que o Estado planeje; c) o planejamento deve definir a expansão desejada dos setores econômicos e os instrumentos de promoção dessa expansão; e d) O Estado deve ordenar também a execução da expansão, captando e orientando recursos financeiros, e promovendo investimentos diretos naqueles setores em que a iniciativa privada seja ineficiente (Bielschowsky, 1988, p. 7).

(3) Bielschowsky (1988), Bresser-Pereira (2006, 2010) e Fonseca (2000, 2004, 2013) são algumas referências essenciais no tratamento do tema. 
Fonseca (2013) revisa a literatura econômica contemporânea dedicada ao estudo do significado do desenvolvimentismo original. Após apreciação das contribuições, argumenta que o desenvolvimentismo deve ser entendido como "a política econômica formulada e/ou executada, de forma deliberada, por governos (nacionais ou subnacionais) para, através do crescimento da produção e da produtividade, sob a liderança do setor industrial, transformar a sociedade com vistas a alcançar fins desejáveis, destacadamente a superação de seus problemas econômicos e sociais, dentro dos marcos institucionais do sistema capitalista" (Fonseca, 2013, p. 28).

Em síntese, de acordo com os autores, a agenda econômica do desenvolvimentismo original era composta por um projeto nacional de desenvolvimento, promovido através da intervenção do Estado, com objetivo explícito de promoção das atividades industriais para melhoria da situação econômica e social de uma nação. É importante ressaltar que não há nas definições apresentadas sobre o conceito de desenvolvimentismo uma caracterização precisa sobre o modelo de financiamento dos investimentos industriais, aspecto que em si já é revelador da existência de divergências, tanto no campo das ideias quanto da implantação das políticas econômicas, sobre o tema. De outro modo, Bielschowsky (1988) e Fonseca (2013) não dão a priori suporte à interpretação de Franco (1996, 2004, 2005) sobre o padrão de financiamento do desenvolvimentismo.

A agenda desenvolvimentista original exerceu influência na definição das políticas econômicas condutoras do processo de substituição de importações, especialmente entre 1945-1964. A crise da década de 1980 e a ascensão do projeto neoliberal na América Latina na década de 1990 reduziram a relevância do desenvolvimentismo no campo das ideias e na definição da agenda de política econômica. A segunda metade da primeira década do século XXI assistiu o ressurgimento da agenda desenvolvimentista no campo das ideias. Sob a liderança do ex-ministro da Fazenda, Luís Carlos Bresser-Pereira, um grupo de economistas heterodoxos dedicou-se à elaboração de uma agenda alternativa à ortodoxia tradicional, o novo desenvolvimentismo.

A definição de novo desenvolvimentismo utilizada neste artigo é uma síntese das contribuições sobre o tema apresentadas por Bresser-Pereira (2006, 2010), Morais e Saad-Filho (2011), Bresser e Gala (2012) e Mollo e Fonseca (2013). O ponto de partida desta corrente de pensamento é entender que as livres forças de mercado são incapazes de conduzir de forma exclusiva o desenvovimento de uma nação. Para o novo desenvolvimentismo, Estado e mercado devem ser parceiros na construção de uma "estratégia nacional de desenvolvimento", que se fundamenta na construção de um conjunto de instituições e políticas orientadas para promoção do desenvolvimento. Não se trata, portanto, de um plano isolado ou de políticas econômicas pontuais. A proposta da estratégia é mais ampla, supõe a construção de 
instituições e a coordenação de um conjunto de políticas econômicas que alcancem, com apoio da sociedade, o objetivo comum de desenvolvimento. Neste contexto, cabe ao Estado um papel "moderado" na realização de investimentos e na definição dos elementos de uma política industrial (Bresser; Gala, 2012).

Em síntese, a construção de uma "estratégia nacional de desenvolvimento" elaborada e executada através da coordenação entre Estado e mercado é o ponto de partida da agenda novo desenvolvimentista. $\mathrm{O}$ detalhamento desta agenda passa pela análise de outro aspecto definidor do "novo desenvolvimentismo" e que pode ser resumido numa assertiva: "a estrutura produtiva importa para o desenvolvimento". Mais especificamente, há nos novos desenvolvimentistas uma recuperação do argumento - originalmente elaborado, entre outros, por Prebisch (1949) e Kaldor (1966) - de que as atividades industriais têm um papel essencial para o desenvolvimento. O "projeto nacional de desenvolvimento" é, em sua essência, um projeto que tem como objetivo específico a consolidação de uma estrutura produtiva industrial.

A inserção da indústria no cenário global de competição pode contar com o apoio de políticas industriais. Há espaço para a promoção destas políticas na agenda novo desenvolvimentista, desde que sejam "limitadas e estratégicas" (BresserPereira; Gala, 2012, p. 53). Além da política industrial, cabe ao Estado um papel ativo na promoção de políticas de distribuição de renda e na definição de uma política de salário-mínimo e de rendas que contribuam para que os salários cresçam com a produtividade. Este processo de crescimento equilibrado entre salários e produtividade é, além de relevante da perspectiva distributiva, importante para uma trajetória estável da dinâmica de preços dos bens e serviços.

Finalmente cabe destacar que a análise novo desenvolvimentista defende que o crescimento deve basear-se na poupança interna, evitando-se o uso de déficits em transações correntes do balanço de pagamentos (poupança externa) como mecanismo de financiamento, tal como argumentado por Bresser-Pereira e Nakano (2003).

O leitor que já tenha familiaridade com o significado do desenvolvimentismo original deve ter notado que a agenda novo desenvolvimentista apresenta diferenças substantivas em relação à versão original. Este aspecto é destacado por Bresser-Pereira e seus seguidores. O novo desenvolvimentismo não pretende ser uma simples retomada da agenda de propostas do desenvolvimentismo original. As mudanças concretas no ambiente econômico e o aprendizado realizado a partir dos equívocos cometidos pelo "velho" desenvolvimentismo são elementos levantados por Bresser para enfatizar um amplo conjunto de diferenças entre novos e "velhos" desenvolvimentistas. Sem pretender esgotar o tema, podem ser apresentados como exemplos destas distinções: 
O desenvolvimentismo original atribuía ao Estado papel de liderança no processo de industrialização, tanto em termos de esforço de planejamento, quanto da realização direta de investimentos. Novos desenvolvimentistas prescrevem um papel mais moderado do Estado;

Enquanto o velho desenvolvimentismo, dado o grau de desenvolvimento incipiente da indústria, advogou e promoveu a industrialização via substituição de importações, o novo desenvolvimentismo pretende expandir a atividade industrial através da promoção de exportações.

A estratégia novo desenvolvimentista não supõe o uso do protecionismo como mecanismo de promoção da indústria, tal como observado no padrão de desenvolvimento industrial vigente na América Latina entre 1945-1980; e

O papel da política industrial no desenvolvimento é mais uma diferença entre novos e velhos desenvolvimentistas. Para os últimos, a política industrial definida e executada sob a liderança do Estado desempenhava papel central no processo de transformação da estrutura produtiva. Enquanto isso, para os novos desenvolvimentistas, a política industrial, elaborada em pareceria com o mercado, deve cumprir um papel "subsidiário e limitado" para estratégia de desenvolvimento.

Mais recentemente, um grupo de economistas do Instituto de Economia da Unicamp, com destaque para André Biancarelli, Pedro Paulo Zahluth Bastos, Pedro Rossi e Ricardo Carneiro, iniciaram a construção de uma proposta alternativa de atualização do desenvolvimentismo batizada de "social desenvolvimentismo" 4 . Em sua essência, a proposta do social desenvolvimentismo pretende "incorporar e enfatizar a dimensão social como elemento central e orientador do desenvolvimento" (Biancarelli; Rossi, 2014, p. 23).

É necessário entender que o ponto de partida do social desenvolvimentismo é a constatação histórica de que "o desenvolvimentismo pode assumir diversas faces como, por exemplo, aquela verificada nas décadas de 1960 e 1970, quando o rápido crescimento econômico que transformou as estruturas produtivas foi acompanhado de uma piora na distribuição de renda" (Biancarelli; Rossi, 2014, p. 23). Carneiro (2012) conclui que a estratégia social desenvolvimentista deve ser assentada em quatro eixos fundamentais: i) melhoria da distribuição da renda; ii) a ampliação da infraestrutura econômica e social; iii) a reindustrialização via adensamento de cadeias e iv) a expansão do setor baseado em recursos naturais.

(4) É necessário reconhecer que parte substantiva da agenda do social desenvolvimentismo tem como ponto de partida a contribuição original de Bielschowsky (2012) e sua proposta de desenho de uma estratégia de desenvolvimento com base na ideia de existência de três frentes de expansão, movidas pela demanda: consumo de massa, recursos naturais e infraestrutura. 
Em síntese, o objetivo final do social desenvolvimentismo é que a promoção do desenvolvimento econômico implique também num efetivo desenvolvimento social, o que no caso brasileiro implica em melhorar os padrões distributivos e reduzir os níveis de miséria.

As diferenças entre o novo e o social desenvolvimentismos são substantivas $^{5}$. As críticas do social desenvolvimentismo às formulações de BresserPereira e dos novos desenvolvimentistas são ácidas. Carneiro (2012, p. 768), por exemplo, classifica como "superficial" a análise novo desenvolvimentista sobre o nacional-desenvolvimentismo. Bastos (2012) classifica o novo desenvolvimentismo como o "desenvolvimentismo exportador do setor privado", enquanto o social desenvolvimentismo é classificado como "o desenvolvimentismo distributivo orientado pelo Estado" já que, segundo o autor, se há algo que unifica esta última corrente é: "a ênfase no mercado interno e no papel do Estado para influenciar a distribuição de renda e a alocação de investimentos" (Bastos, 2012, p. 794).

O social desenvolvimentismo promove, portanto, um regaste mais próximo das ideias do desenvolvimentismo original quando comparado ao novo desenvolvimentismo, especialmente no que tange a dois campos: 1) Na ênfase no mercado interno enquanto determinante da dinâmica econômica brasileira e 2) No papel mais amplo concedido à ação do Estado na economia, especialmente no que tange à alocação de recursos para investimentos e para a distribuição da renda.

Em relação ao primeiro aspecto, cabe destacar que o social desenvolvimentismo é crítico, dadas as condições concretas de funcionamento da economia, da estratégia de crescimento puxado pela demanda externa. Este ponto é apresentado por Bastos (2012) e sintetizado por Biancarelli e Rossi (2014, p. 27) ao sustentarem que: "Mesmo que fosse possível transformar uma economia como a brasileira em export-led growth apenas com a política macroeconômica e o custo do trabalho, as condições atuais de concorrência internacional exigiriam alterações de tal monta nestas variáveis que o resultado certamente seria uma recessão doméstica. E o que é pior, acompanhada pela regressão em vários dos avanços conquistados pelo país nos últimos anos e que contribuíram para o seu crescimento".

Tendo em mente estes conceitos, é possível aprofundar a discussão sobre o tema específico do equilíbrio fiscal nas distintas correntes de pensamento, tal como informado na introdução do trabalho.

(5) As distinções existentes no campo específico das políticas econômicas serão abordadas na próxima seção. 


\section{A questão fiscal nos expoentes intelectuais do desenvolvimentismo original (1945-1964)}

Esta seção é dedicada à análise do pensamento econômico dos expoentes intelectuais do desenvolvimentismo original sobre o tema específico do papel atribuído aos desequilíbrios fiscais como modo de financiamento dos investimentos industriais necessários para o processo substituição de importações e superação do subdesenvolvimento. Roberto Simonsen, Roberto Campos e Celso Furtado são considerados, de acordo com Bielschowsky (1988), os líderes intelectuais das três correntes principais do pensamento desenvolvimentista, respectivamente: o desenvolvimentismo do setor privado, o do setor público não nacionalista e o do setor público nacionalista

Roberto Simonsen foi o patrono do desenvolvimentismo brasileiro. As ideias centrais do que no período do pós-guerra viriam a se constituir nas bases do pensamento econômico desenvolvimentista já se encontravam presentes, ainda que de forma embrionária, em seu trabalho intelectual. A defesa da industrialização como forma de superação do subdesenvolvimento e o papel ativo do Estado, especialmente o esforço de planejamento, como forma de superar os obstáculos ao projeto industrializante impostos pela fragilidade do capital privado nacional, já estavam presentes na obra de Roberto Simonsen, antes do desenvolvimento das contribuições teóricas da Cepal.

A recuperação do contexto histórico internacional no qual o pensamento de Simonsen foi forjado é essencial para sua compreensão. As décadas de 1930 e 1940 foram marcadas pela ascensão do planejamento econômico, em grande medida associado aos resultados do "New Deal" nos Estados Unidos e à superação da grave crise econômica iniciada em 1929. A planificação decorrente do esforço de guerra é outro elemento que deve ser levado em conta neste contexto de auge do planejamento. Além do contexto histórico, é importante sublinhar que no campo intelectual, especialmente na academia norte-americana, a década de 1940 foi marcada pela relevância do planejamento como forma de organização social, tal como destacam Cavalieri e Curado (2015).

Os contextos históricos, de desenvolvimento e de difusão das ideias, são relevantes para entender porque, de acordo com Simonsen, era necessário avançar na "planificação da economia brasileira em moldes capazes de proporcionar os meios adequados para satisfazer as necessidades essenciais de nossa população" (Simonsen [1945], 2010a, p. 44). Maza (2002) argumenta que Simonsen enxergava na planificação um método científico para enfrentar e superar o subdesenvolvimento. $\mathrm{O}$ autor defendia explicitamente que "a ciência e a técnica modernas fornecem seguros elementos para o delineamento desta planificação" (Simonsen [1945], 2010a, p. 44). 
A ênfase no planejamento econômico como um método científico de superação do subdesenvolvimento é tema tratado pela literatura especializada no autor $^{6}$. A análise com foco explícito no papel da política fiscal para o autor é elaborada apenas marginalmente pela literatura especializada, ainda que esta questão estivesse presente em sua obra.

Simonsen tinha consciência que seu projeto de desenvolvimento teria custos para o Estado. Vale ressaltar que a intervenção defendida por Simonsen não se limitava ao campo do planejamento. Caberia ao Estado realizar os investimentos em atividades produtivas, especialmente nas indústrias de base, dada a fragilidade do capital privado nacional. Como financiar estes investimentos? Simonsen faz explicitamente esta indagação em seu clássico debate com Eugênio Gudin nas "controvérsias do planejamento".

Antes de responder este questionamento, é importante retomar alguns elementos do contexto histórico internacional. $\mathrm{O}$ fim do conflito mundial consolidou no país a expectativa de que o apoio concedido aos aliados durante a guerra colocaria o Brasil no rol de nações que receberiam recursos, especialmente norte-americanos, para o desenvolvimento doméstico. A expectativa nos primeiros anos do governo Dutra de apoio para o projeto de desenvolvimento nacional, especialmente através de empréstimos internacionais, é tema fartamente documentado pela literatura econômica, na conhecida discussão sobre "ilusão de divisas" 7 .

Simonsen, tal como outros analistas, também acreditou que no contexto internacional do pós-guerra o Brasil, assim como outros países, contaria com apoio dos EUA para financiar os investimentos industriais. Vale lembrar que a Missão Cooke, realizada em 1942 e liderada por técnicos de planejamento do governo dos EUA, defendia a industrialização da economia brasileira como forma de promoção do desenvolvimento, tema recorrentemente recuperado nos trabalhos de Simonsen. O autor fez questão de sublinhar a conclusão central da Missão Cooke e sua indicação favorável ao processo de industrialização: “A industrialização do país, sábia e cientificamente conduzida, com um melhor aproveitamento dos recursos naturais, é o meio que a Missão aponta para alcançar o progresso desejado por todos" (Simonsen [1945], 2010a, p. 39).

A preocupação com o tema do financiamento encontra-se explícita no documento: "A planificação da economia brasileira" publicado originalmente em 1945 e que deu início ao debate com Eugênio Gudin, no que posteriormente ficou conhecido como a "controvérsia do planejamento". A proposta de Simonsen era clara: "para início de um tal programa, poderia o Brasil empenhar pelo menos 50\%

(6) Para uma leitura mais profunda do tema recomenda-se a leitura dos trabalhos de Carone (1971); Maza (2002); Teixeira, Maringoni e Gentil (2010).

(7) Sobre o tema recomenda-se a leitura de Vianna e Villela (2011) 
das disponibilidades do país no exterior" (Simonsen [1945], 2010a, p. 46). É interessante notar que, de acordo com o autor, a elevação da atividade produtiva ajudaria a "diminuir os efeitos das emissões já realizadas e conter as atuais fontes inflacionarias".

A negociação de empréstimos com os Estados Unidos era outro elemento central da proposta de financiamento dos projetos industriais para Simonsen. "A obtenção do financiamento geral poderia ser negociada com os Estados Unidos... a operação deveria ser negociada em moldes diferentes dos empréstimos habituais... os juros seriam, inicialmente substituídos pela participação nos resultados das explorações industriais" (Simonsen [1945], 2010a, p. 46).

A ênfase na necessidade de promover o financiamento dos investimentos industriais através de empréstimos norte-americanos cresceu após o fim da II guerra mundial. No contexto de aplicação do Plano Marshall para reconstrução da Europa, Simonsen defendeu que: "as nações latino-americanas devem pleitear a organização de uma Comissão de Cooperação Econômica que estude os meios para tornar mais eficiente uma efetiva cooperação dessa natureza entre os países americanos, e a obtenção de auxílio norte-americano, para os seus planos de desenvolvimento econômico" (Simonsen, 1947, p. 16).

A necessidade de expansão para a América Latina da política de financiamento do desenvolvimento promovida para Europa pelo Plano Marshall foi tema recorrente da participação de Simonsen no debate econômico nos últimos anos de sua vida. O tema foi discutido nos trabalhos: "O Plano Marshall e suas prováveis repercussões econômicas na América Latina", "A situação econômica da América Latina e suas possibilidades em face do Plano Marshall" e finalmente "O Plano Marshall e um novo critério nas relações internacionais", publicados entre os anos de 1947 e 1949.

Simonsen era um crítico da exclusão da América Latina do Plano Marshall. Sua argumentação combinava aspectos econômicos, especialmente o atraso relativo da região em relação ao continente europeu, e geopolíticos ao sustentar que a estabilidade política na região dependia do desenvolvimento das atividades produtivas, especialmente dos avanços da industrialização. $O$ autor também criticava o argumento que a retomada do crescimento nos países centrais ajudaria indiretamente à região através da expansão de suas exportações. Para Simonsen, a mera expansão das exportações na América Latina, o principal efeito indireto da retomada do crescimento nos países centrais, promoveria "retardamento de nosso desenvolvimento econômico pela manutenção indefinida de nossa estrutura semicolonial" (Simonsen, 1949, p. 20).

Em síntese, a leitura das contribuições de Simonsen nas "controvérsias do planejamento" entre 1944 e 1945 e de suas contribuições posteriores ao conflito 
mundial, especialmente entre 1947 e 1949, deixam evidente o foco na tomada de empréstimos junto ao governo dos Estados Unidos como elemento chave da estratégia de financiamento do projeto industrializante. Não há no patrono do desenvolvimentismo brasileiro a defesa da utilização de déficits públicos como mecanismo de financiamento do projeto de industrialização. Pelo contrário, há uma nítida preocupação com o equilíbrio das finanças públicas. $\mathrm{O}$ autor recomenda explicitamente que os pagamentos das amortizações dos empréstimos devem "ser condicionados ao aumento da produtividade resultante da organização econômica do país" (Simonsen [1945], 2010a, p. 47).

Roberto Campos é apresentado por Bielschowsky (1988) como o principal expoente intelectual do grupo de "desenvolvimentistas não nacionalistas". Polêmico e partícipe privilegiado do processo de industrialização brasileira, Campos em seu livro de memórias, apesar de elogiar o "acurado" trabalho de Bielschowsky afirma que: "a expressão liberal desenvolvimentista teria sido talvez a verbiagem mais acurada" (Campos, 1994, v. I, p. 168).

O "desenvolvimentismo não nacionalista" do qual Campos era o líder intelectual baseava-se em duas premissas básicas.

A primeira é que, nos países subdesenvolvidos da América Latina, como também em outros países subdesenvolvidos, uma intervenção muito maior do Estado é desejada e necessária do que no caso de economias maduras como os Estados Unidos. Essa necessidade para maior intervenção estatal existe ainda que, o nível de eficiência governamental é muito mais baixo. As razões por trás disso não são somente o fato de que áreas tradicionais de investimento... são de importância muito grande nos primeiros estágios do desenvolvimento, mas também em investimentos diretamente produtivos há necessidade de incentivo especial e ação governamental (Campos, 1967, p. 50).

Além das áreas tradicionais de investimento, o autor apresenta quatro campos específicos para realização de investimentos do Estado, a saber: 1) "Os pioneiros", tais como novas fontes energéticas, 2) "Os preclusivos", que tinham como objetivo impedir a criação de monopólios privados através da criação de monopólios públicos, 3) "O supletório", no qual o investimento público suplementaria os esforços iniciados pelo setor privado, aumentando sua escala de produção, como por exemplo, no caso do aço e 4) Os "expiatórios" que teriam como objetivo a eliminação de "pontos de estrangulamento" em diversos setores da economia. Os investimentos do Estado deveriam ser limitados aos quatro campos apresentados. Este é um aspecto essencial da contribuição intelectual de Campos em sua fase desenvolvimentista. Apesar de defensor da intervenção direta do Estado na economia, há uma evidente preocupação do autor em estabelecer limites para esta intervenção. 
Bielschowsky (1988) e Godoi (2007) sustentam que o autor era um crítico do planejamento global defendido na época pelos estudos cepalinos. Para Campos, o planejamento dos investimentos do Estado deveria seguir a metodologia do "planejamento seccional", ou seja, deveria ser essencialmente um planejamento de investimentos em nível setorial. Entre os argumentos selecionados por Campos (1967) para justificar esta metodologia, aparecem com frequência a redução da possibilidade de erro de análise no planejamento setorial em relação ao geral e as dificuldades oriundas das diferenças regionais existentes no Brasil. Além disso, é sempre bom ter em conta que Campos recorrentemente elencava a ineficiência do Estado brasileiro como justificativa para limitar sua intervenção na economia.

É importante enfatizar as diretrizes que deveriam guiar o "planejamento seccional". Godoi (2007, p. 72, grifo nosso) ao sintetizar as características centrais do que seria este planejamento seccional, argumenta que para Campos: "dever-se-ia obter os recursos por meios não inflacionários, como impostos, endividamento interno e não por déficits públicos", deixando claro que a leniência com o desequilíbrio fiscal não fez parte das proposições do autor.

Além das contribuições intelectuais, no caso de Campos, é relevante apresentar sua ação como gestor de política econômica. O capítulo IX de seu "Lanterna na Popa (Memórias) " é dedicado à análise de sua ativa participação no governo de Juscelino. Campos desempenhou ao lado de Lucas Lopes um papel central neste período, especialmente no desenho do Plano de Metas. É interessante notar que, ao contrário de outras análises sobre o significado do Plano, tal como a visão de Carlos Lessa de que este constituiu o mais audacioso e complexo esforço de planejamento empreendido no país, para Campos o Plano de Metas foi essencialmente um plano de enfrentamento dos desequilíbrios de natureza setorial que limitavam o desenvolvimento econômico.

Campos apresenta-se em suas memórias como um crítico da falta de preocupação do Plano de Metas, em função da orientação do presidente Juscelino, com o equilíbrio macroeconômico. Afirma enfaticamente que: "O Plano de Metas foi validamente criticado, à sua época, por ser essencialmente um programa setorial, sem adequada análise macroeconômica... Tanto Lucas Lopes como eu tínhamos consciência da necessidade da formulação de medidas macroeconômicas, de modo a compatibilizar o Plano de Metas com um razoável grau de estabilidade de preços e viabilidade cambial" (Campos, 1994, v. I, p. 269). Dentre as medidas de natureza macroeconômica, o autor destaca: "uma austera programação monetária e fiscal".

O comprometimento de Campos com o equilíbrio das contas públicas, especialmente como forma de controlar o processo inflacionário, está explícito no Programa de Estabilização Monetária (PEM) preparado entre julho e setembro de 1958. Segundo Campos, a "correção do desequilíbrio financeiro do setor público" 
apresentava-se como essencial para o controle da inflação. O Programa oferecia recomendações com o objetivo de "limitação de despesas e acréscimo de receita, visando sempre a compatibilizar o programa de estabilização com a execução das metas" (Campos, 1994, v. I, p. 348).

Em síntese, não pode restar dúvida que dos expoentes intelectuais do desenvolvimentismo original, Campos foi aquele que de forma mais enfática afastou-se - tanto no plano das ideias quanto das ações concretas enquanto gestor de política econômica - de qualquer proposta de uso de déficits públicos como mecanismo de financiamento do projeto de industrialização. Dentre as razões que justificam este afastamento, encontram-se de forma recorrente na obra de Campos do período duas razões básicas: 1) A visão de ineficiência do Estado e 2) A associação entre os desequilíbrios fiscais e o processo inflacionário.

Assim como nas análises anteriores, para entender a questão fiscal em Celso Furtado, torna-se essencial investigar alguns aspectos gerais da obra do autor. No período analisado de auge do ciclo ideológico do desenvolvimentismo, a obra de Furtado foi marcada pela ênfase no papel da deterioração dos termos de troca como elemento chave na configuração dos desequilíbrios econômicos latino-americanos.

No desenvolvimento da economia brasileira desempenharam papel decisivo três fatôres cuja ação se vem fazendo sentir secularmente: a) uma persistente piora na relação de trocas; b) uma elevação não menos persistente da taxa cambial; e c) uma inflação crônica do meio circulante, motivada em grande parte por déficits orçamentários. Estes três fatôres estão intimamente relacionados entre si, e, embora não seja possível estabelecer uma relação causal necessária entre os mesmos, há múltiplas indicações de que do primeiro dêles procede, o mais das vêzes, a principal fôrça de desequilíbrio (Furtado, 1950, p. 7).

O vínculo entre os desequilíbrios externos e os resultados fiscais é estabelecido por Furtado (1950) ao ressaltar que a arrecadação do Estado no período era altamente correlacionada com o nível de atividade doméstica e com os resultados do setor externo, dada a importância dos impostos sobre importação na composição da receita fiscal. As crises externas e a decorrente contração da renda e das importações acabavam gerando como subproduto os déficits fiscais. O resumo do tema é feito pelo autor da seguinte forma: “À depressão cíclica nos países industriais corresponde uma diminuição brusca nos preços dos produtos primários que o Brasil exporta. O impacto dessa diminuição se traduz por uma contração nas entradas dos grandes exportadores e indiretamente - seja pela diminuição da atividade interna, seja pela redução das importações - nos réditos do Tesouro" (Furtado, 1950, p. 9).

A saída encontrada por Furtado para a solução do problema encontrava-se na alteração da estrutura produtiva, através da promoção da industrialização e a consequente alteração do papel do país na divisão internacional do trabalho. A 
industrialização seria, portanto, a chave para a superação do histórico processo de deterioração dos termos de troca e das crises de balanço de pagamentos e seus efeitos deletérios sobre as contas públicas.

Furtado (1952) em texto que discute uma série de conferências proferidas pelo professor da Columbia University, Ragnar Nurkse, analisa os limites para o desenvolvimento econômico em países subdesenvolvidos. O argumento central desenvolvido por Furtado é que a reduzida capacidade de realizar investimentos, decorrente do baixo nível de poupança, constituía-se num elemento chave para entender os limites do desenvolvimento. De acordo com o autor:

Não são incentivos para inverter o que falta em nossa economia. Faltam sim estímulos a poupar. Dados os fortes estímulos para consumir que nos vêm das economias mais avançadas e que tão bem explica o professor NURKSE, muito dificilmente nossa economia poderá chegar espontaneamente, na atual fase de desenvolvimento, a um alto nível de poupança. Se desejamos caminhar para um desenvolvimento mais intenso e equilibrado, temos que colocar em primeiro plano o problema de poupança (Furtado, 1952, p. 35, grifo nosso).

Assim, o reduzido estímulo a poupar, decorrente do padrão imitativo de consumo das sociedades latino-americanas, foi apresentado por Furtado (1952) como um dos principais entraves ao desenvolvimento econômico. A solução do problema do financiamento dos investimentos encontrava-se na elevação do nível de poupança ${ }^{8}$. Furtado, portanto, não propõe a mera expansão fiscal ou a utilização de qualquer mecanismo de financiamento via expansão monetária para solucionar o problema do baixo nível de inversões.

Outro aspecto que merece destaque em seu trabalho de 1952 diz respeito à defesa de um papel ativo do governo no direcionamento dos investimentos produtivos, dada a alocação ineficiente gerada pelo "sistema de preços" numa economia subdesenvolvida. A rigor, o autor sustenta que este sistema é eficiente na alocação de recursos em países desenvolvidos, nos quais há igualdade entre produtividade marginal e social. Esta última se refere a "um critério social de efeito sobre o conjunto da renda nacional da última unidade de inversão".

Numa economia altamente desenvolvida... a produtividade social de uma inversão deve aproximar-se de sua produtividade do ponto de vista da empresa. Neste caso o simples mecanismo dos preços pode ser um guia seguro para as inversões. O mesmo não ocorre com uma economia em etapas primárias do desenvolvimento. Nesta última existe uma grande

(8) Importante notar que, de acordo com o autor, "um país como o Brasil tem uma grande margem potencial de poupança, a qual está apenas esperando por formas compulsórias de captação" (Furtado, 1952, p. 35). O autor, no entanto, não aprofunda sua análise sobre como promover ou quais seriam precisamente estas "formas compulsórias de captação". 
disparidade no grau de utilização dos fatores produtivos, de um setor para outro. A simples translação de fatores de produção ou a introdução de novas combinações entre estes podem determinar substanciais aumentos na produtividade social. Esses aumentos, entretanto, não se refletem na rentabilidade das empresas. Existem, portanto, fortes razões para crer que o ritmo de desenvolvimento pode ser intensificado se corrige a insuficiência do mercado como mecanismo diretor do processo econômico e se se imprime às inversões uma orientação geral coordenadora (Furtado, 1952, p. 29).

A discussão sobre o tema do financiamento dos investimentos foi aprofundada em seu livro "Desenvolvimento e Subdesenvolvimento" publicado em $1961^{9}$. No que tange ao tema mais relevante para este artigo, a questão do financiamento dos investimentos, destaca-se uma importante alteração ${ }^{10}$ na visão do autor em relação ao seu posicionamento no trabalho de 1952. Furtado (1961) assume novamente que o elevado padrão de consumo da classe capitalista nos países subdesenvolvidos, como o Brasil, era um limitador da capacidade de acumulação. No entanto, o autor argumenta que a taxa de lucro da economia seria suficientemente alta para garantir o financiamento dos investimentos. "Não obstante o elevado nível de consumo das classes proprietárias, a taxa de lucro é suficientemente elevada para permitir um grande volume de inversões, através do sistema de autofinanciamento" (Furtado, 1961, p. 258).

A combinação de uma oferta totalmente elástica de mão-de-obra com uma tecnologia poupadora de trabalho seria o elemento chave para explicar porque no Brasil, assim como em outros países subdesenvolvidos, os salários reais dos trabalhadores se mantiveram de maneira geral estáveis. Neste contexto, os ganhos de produtividade gerados pela expansão das atividades industriais foram transferidos quase que integralmente para os empresários na forma de elevação da taxa de lucro. Apesar de contribuir para o financiamento dos investimentos industriais, os níveis elevados das taxas de lucro gerariam efeitos deletérios para a economia brasileira, especialmente no que tange à evolução da produtividade:

Num clima de negócios em que predomina uma elevada taxa de lucros e no qual não se manifestam pressões para reduzir essa taxa, a preocupação com a produtividade é sempre relegada a segundo plano, o que constitui vício fundamental em um sistema industrial. Na ausência de preocupação predominante com a produtividade, os problemas da escolha de tecnologia, de adequada localização, enfim todos os critérios de racionalidade, são relegados a segundo plano. O que vem a ser o mesmo que afirmar que todo o desenvolvimento se faz com elevado custo social (Furtado, 1961, p. 258).

(9) O livro é formado por uma coletânea de textos, alguns já publicados, como por exemplo Furtado (1952), e outros inéditos, como o capítulo 6.

(10) Esta alteração é observável na leitura do capítulo 6, escrito em 1960. 
Para finalizar o tema do financiamento em Furtado (1961), é relevante lembrar a discussão sobre o mecanismo de transferência via "poupança forçada". A elevação dos preços ao longo do tempo, ou seja, o processo de inflação, funcionou de acordo com Furtado como um elemento adicional de financiamento dos investimentos privados. A elevação dos preços promoveu a transferência de renda dos trabalhadores para os empresários industriais, contribuindo para a acumulação de capital e o financiamento dos investimentos produtivos ${ }^{11}$. "Não cabe afirmar que a inflação tenha sido necessária à industrialização. Teoricamente, poder-se-ia conceber um modelo de desenvolvimento para o Brasil, no período considerado, ainda mais intenso, sem inflação. Mas o que não resta dúvida é que a industrialização que se realizou apoiou-se na inflação" (Furtado, 1961, p. 253-254).

É importante explorar também a relação entre a inflação e a questão fiscal no autor. A visão de que a inflação latino-americana era causada por fatores estruturais ligados ao rápido processo de substituição de importações foi a base para a crítica estruturalista à concepção monetarista que atribuía à expansão monetária derivada do financiamento dos déficits públicos a causa central do processo inflacionário. Dialeticamente a causa (e a solução) da inflação na América Latina no início dos anos 1950 encontrava-se no processo de substituição de importações, já que a conclusão deste processo reduziria de modo relevante às causas estruturais da inflação brasileira.

Boianovsky (2012) apresenta evidências da alteração no pensamento de Furtado sobre as causas da inflação e, especialmente sobre o papel dos desequilíbrios fiscais, no final da década de 1950 e início dos anos $1960^{12}$. A participação de Furtado na conferência do Rio de Janeiro em 1963 é apontada por Boianovsky (2012) como uma evidência importante deste processo, pois neste evento Furtado afirmou que o desequilíbrio fiscal era a causa primária do processo de inflação ${ }^{13}$. Curado e Cavalieri (2015) apontam evidências sobre a preocupação de Furtado com a inflação, especialmente por esta ser entendida como um processo de transferência de renda dos trabalhadores para a classe proprietária e, portanto, promotora de concentração da renda.

(11) Curado e Cavalieri (2015) apresentam evidências que o autor - apesar de reconhecer que a inflação “não foi exterior ao processo de industrialização: serviu-lhe de instrumento de remoção de obstáculos”(Furtado, 1961, p. 254) - não pode ser acusado de promover ou defender o uso de mecanismos inflacionários para o financiamento dos investimentos. Furtado é bastante crítico em relação ao uso destes expedientes, sobretudo por seus efeitos deletérios em termos de distribuição da renda.

(12) De modo mais preciso esta alteração ocorreu pela primeira vez numa entrevista concedida originalmente para um jornal brasileiro em 1958 e posteriormente reproduzida em 1959 pela revista El Trimestre Económico. (Boianovsky, 2012, p. 310).

(13) "Its primary cause lies in a deep disequilibrium for the public sector, witch was called forth to take up concrete responsibilities in the process of capital formation, without regard to the fact that the fiscal apparatus had not undergone the necessary adaptation" (Furtado, 1964, p. 498 apud Boianovsky, 2012, p. 310). 
O papel desempenhado por Furtado na vida pública, especialmente sua participação como ministro do planejamento e responsável pela elaboração do Plano Trienal, também deve ser levado em consideração na discussão sobre a visão do autor sobre temas como equilíbrio fiscal e inflação. O diagnóstico apresentado por Furtado para a inflação brasileira no início da década de 1960 era baseado em dois elementos centrais: 1) A redução da capacidade de importação no contexto da aceleração do processo de substituição de importações do final da década de 1950 e 2) O déficit fiscal financiado por expansão monetária (Presidência da República, 1962).

A redução no déficit fiscal e o controle do crescimento dos agregados monetários eram elementos chaves do programa de combate à inflação do Plano Trienal. O uso de instrumentos até então preconizados pela literatura monetarista gerou muitas críticas e polêmicas. Bresser-Pereira (2006, p. 15) apresenta com clareza este ponto ao afirmar que: "quando Celso Furtado, diante da grave crise do início da década de 1960, propôs o Plano Trienal, foi considerado por esses seguidores de segunda categoria como tendo sofrido uma recaída ortodoxa. $\mathrm{Na}$ verdade, Furtado já pensava no equilíbrio fiscal. Defende-o não por ortodoxia, mas porque sabe que o Estado é o instrumento de ação coletiva por excelência da nação".

A participação de Furtado na vida pública e a leitura dos trabalhos apresentados, especialmente Furtado (1950, 1952, 1959, 1961), fornecem evidências que ajudam a desmistificar a visão do autor enquanto defensor da utilização de desequilíbrios fiscais crônicos para o financiamento dos investimentos industriais.

Ainda que extrapole o recorte temporal proposto, é bom lembrar que estas evidências persistem nas obras posteriores do autor, tal como em seu livro: “Análise do Modelo Brasileiro" publicado em 1972. O autor dedica uma seção exclusiva do livro para a discussão do "financiamento da industrialização". Furtado enfatiza o papel central desempenhado pelas políticas econômicas adotadas pelo Estado para o financiamento das atividades industriais. A conclusão apresentada em Furtado (1972, p. 25) é que: "Os recursos para o financiamento das indústrias substituidoras de importações eram, assim, retirados do setor exportador, mediante taxas diferenciais de câmbio, e ao conjunto da população, em consequência da elevação dos preços relativos dos bens cuja oferta estava sendo restringida". Além do efeito da política cambial e do mecanismo de transferência inflacionaria, o autor destaca o papel central do Estado no financiamento dos investimentos através das ações do Banco Nacional de Desenvolvimento Econômico "cujos recursos eram retirados compulsoriamente de pessoas físicas contribuintes do Imposto de Renda... emprestou à grande indústria massa considerável de recursos que, em razão da inflação, assumia a forma de doações de capital” (Furtado, 1972, p. 25). 
Assim, a ideia presente em Franco (1996, 2005) que Furtado, assim como outros intelectuais desenvolvimentistas, era leniente no trato da questão fiscal, não encontra sustentação numa análise mais acurada da obra do autor e em sua participação ativa na vida pública. No campo das ideias, a análise apresenta evidências de que Furtado privilegiou outros mecanismos como relevantes para o financiamento dos investimentos. Como em todos os temas analisados ao longo de sua obra, a visão de Furtado muda conforme a evolução da história (Boianovsky, 2012; Coelho; Granziera, 2009). É assim que podemos entender porque em 1952 o autor chama atenção para um problema de escassez de poupança, elemento que em sua obra de 1961 deixa de ser relevante dadas as transformações procedidas na economia, especialmente a elevação da taxa de lucro. Finalmente em seu trabalho de 1972, aparece com maior destaque o papel exercido pelo BNDE no financiamento dos investimentos. No plano concreto, as ações para combater a inflação no Plano Trienal, especialmente no campo fiscal, não podem deixar dúvida sobre a inadequação da tese da leniência fiscal apresentada por Franco (1996, 2005).

Em síntese, a revisão dos trabalhos originais e da literatura especializada, assim como a discussão sobre a participação na vida pública brasileira, permitem concluir que os expoentes intelectuais do desenvolvimentismo original não podem ser associados a um tratamento leniente com as contas públicas. Especialmente importante é a apresentação de evidências de que os expoentes intelectuais do desenvolvimentismo não preconizaram a utilização de desequilíbrios fiscais como mecanismo de financiamento dos investimentos produtivos. Roberto Simonsen, Roberto Campos e Celso Furtado sugeriram a utilização de mecanismos distintos de financiamento, que foram desde a tomada de empréstimos dos Estados Unidos e aumento de impostos até a observação de que parte do financiamento seria realizado pela elevada taxa de lucro vigente na economia local.

\section{A questão fiscal no novo e no social desenvolvimentismos}

Esta seção apresenta a discussão no novo e no social desenvolvimentismos. Tendo em vista a natureza da discussão e a relação da questão fiscal com outras áreas, são estabelecidas considerações preliminares sobre as políticas monetária e cambial nestas correntes.

Para que a inserção competitiva da indústria no cenário internacional ocorra, é essencial, de acordo com os novos desenvolvimentistas, que os fundamentos macroeconômicos do país forneçam condições adequadas de competitividade para a indústria. A política macroeconômica proposta pelos novos desenvolvimentistas deve, sem deixar de considerar a estabilidade de preços, fornecer estas condições para competição externa. A combinação de taxas de juros elevadas e câmbio valorizado, recorrentemente verificada na conjuntura econômica brasileira, é uma das raízes para as dificuldades competitivas da indústria e para o baixo crescimento 
econômico do país. A política macroeconômica é parte integrante e essencial da estratégia de nacional desenvolvimento, fornecendo, além da estabilidade de preços, taxas de juros e de câmbio competitivas em âmbito internacional (Bresser-Pereira; Gala, 2012).

O novo desenvolvimentismo apresenta-se, portanto, como uma alternativa à ortodoxia macroeconômica. Seu objetivo final é a promoção de uma "estabilidade macroeconômica" que, além da estabilidade de preços, estabeleça uma trajetória sustentável de crescimento econômico. É necessário enfatizar que a estabilidade macroeconômica é "um conceito mais amplo do que o de mera estabilidade de preços, ou seja, deve procurar também reduzir as incertezas relativas à demanda futura, que são inerentes aos negócios na economia" (Oreiro; De Paula, 2012, p. 59). Estes objetivos devem ser alcançados através do manejo adequado das políticas fiscal, monetária e cambial.

No campo monetário, o argumento novo desenvolvimentista enfatiza o triplo mandato do Banco Central. A política monetária deve contribuir para gerar simultaneamente um nível adequado de inflação, emprego e uma taxa de câmbio promotora da competitividade externa da indústria nacional. Dada a "impossibilidade da santíssima trindade", a proposta de controle simultâneo de juros e câmbio supõe a implantação de regimes de controle sobre os fluxos de capital, assim como a utilização de instrumentos de política cambial ativa, tais como a compra de reservas.

Ferrari Filho e Paula (2012), por exemplo, defendem a adoção de mecanismos de controle de capitais e a criação de mecanismos que atenuem as flutuações da taxa de câmbio. Os autores sugerem, por exemplo, a criação de um Fundo de Estabilização Cambial (FEC) para atuar como um market maker no mercado de câmbio. Bresser-Pereira (2010) argumenta que o sucesso econômico de alguns emergentes, especialmente as experiências do sudeste asiático, foi fruto da opção por administrar o sistema cambial e não permitir a valorização de suas moedas. Da mesma forma, as nações emergentes que não foram capazes de controlar adequadamente a evolução da taxa de câmbio real fracassaram na promoção do crescimento.

Em síntese, taxas de juros e de câmbio ocupam um papel central na análise macroeconômica novo desenvolvimentista. Taxas de juros reais elevadas promovem a entrada de capital de curto prazo contribuindo para a valorização da moeda e a redução da competitividade externa. O cenário é ainda mais grave quando combinado com elevação nos preços das commodities, tal como observado entre 2001 e 2011. Não é exagero afirmar que para os novos desenvolvimentistas, neste período, as elevadas taxas de juros e o câmbio valorizado constituíram-se nos principais obstáculos da política macroeconômica para o desenvolvimento brasileiro. 
Para os novos desenvolvimentistas, o equilíbrio fiscal é essencial para uma trajetória de crescimento equilibrado de longo prazo. Bresser-Pereira e Gala (2012, p. 43) sintetizam este tema na tese n. 13 do novo desenvolvimentismo: Responsabilidade Fiscal: "O déficit público enfraquece o Estado e causa inflação, devendo ser evitado, a não ser em momentos de recessão”. A defesa desta tese parte de uma releitura da questão fiscal em Keynes. De acordo com os autores, na década de oitenta desenvolveu-se no Brasil um "keynesianismo vulgar que criticava os economistas ortodoxos por defenderem a responsabilidade fiscal e propunha déficits fiscais crônicos para combater a insuficiência da demanda" (Bresser-Pereira; Gala, 2012, p. 43). A interpretação novo desenvolvimentista é clara neste ponto: Keynes nunca defendeu a ocorrência de déficits públicos crônicos. A utilização de gastos acima das receitas públicas deveria ser restrita aos momentos de recessão, uma típica recomendação de política fiscal anticíclica.

No campo fiscal, a crítica novo desenvolvimentista à ortodoxia refere-se a ênfase concedida para a obtenção de superávits primários. Para os novos desenvolvimentistas “o ajuste fiscal não visa um mero superávit primário, mas a uma poupança pública positiva. Implica não apenas a redução das despesas correntes, mas também da taxa de juros" (Bresser-Pereira; Gala, 2012, p. 54). É por esta razão que a discussão fiscal novo desenvolvimentista é indissociável da discussão sobre a política monetária, especialmente sobre os patamares de taxa real de juro, já que um esforço para redução das despesas primárias poderia ser anulado pela execução de uma política monetária que determinasse patamares elevados da taxa real de juro.

Finalmente, resta analisar a discussão fiscal da perspectiva do social desenvolvimentismo. Para tanto são necessárias algumas considerações preliminares. O social desenvolvimentismo adota como ponto de partida que as considerações sobre a política macroeconômica, assim como as discussões mais gerais sobre o desenvolvimento, não podem ser feitas em abstrato, sendo fundamental levar em consideração as condições concretas de funcionamento da economia, especialmente da economia internacional, pois para esta corrente: "o contexto externo molda as opções das três frentes de política (cambial, monetária e fiscal) e, mais do que isso, condiciona os determinantes do crescimento brasileiro" (Biancarelli e Rossi, 2014, p. 25).

A política fiscal do social desenvolvimentismo deve cumprir um amplo conjunto de objetivos. Além de ser utilizada como instrumento anticíclico, cabe também à política fiscal resguardar o espaço fiscal necessário para a realização de investimentos públicos, motor de expansão da economia. "Além disso, toda a ênfase na infraestrutura social e nos serviços públicos aqui defendida como norte de um social desenvolvimentismo requer recursos fiscais significativos para sua efetivação". (Biancarelli; Rossi, 2014, p. 31). 
O social desenvolvimentismo reconhece, portanto, a existência de uma demanda significativa de recursos fiscais para a implantação de sua agenda. Isto, no entanto, não os leva a argumentarem a favor de desequilíbrios fiscais como mecanismo de financiamento do desenvolvimento. Carneiro (2012, p. 772), por exemplo, ao discutir a estratégia proposta pelo novo desenvolvimentismo afirma que: "Sugere-se ainda, aliás corretamente, que os déficits públicos permanentes como estímulo à demanda deveriam ser evitados".

Biancarelli e Rossi (2012) concentram sua discussão sobre o tema no caráter contraproducente para o desenvolvimento econômico da adoção de metas fiscais de superávit primário anual autônomas em relação ao ciclo econômico. O argumento parte da constatação factual de que as receitas do governo têm caráter pró-cíclico. Desta forma, em períodos recessivos, a queda da arrecadação promove, para cumprir a meta fiscal de curto prazo, uma redução dos gastos, o que contribui para aprofundar a recessão e piorar ainda mais a situação fiscal.

A adoção da meta fiscal anual impede, portanto, a operação do mecanismo anticíclico, assim como inviabiliza a realização de investimento públicos, nos períodos de recessão. Por outro lado, em períodos de aceleração do crescimento, a elevação das receitas tributárias poderia gerar um excesso de gastos desnecessários. O social desenvolvimentismo considera, portanto, inadequada a adoção de uma política fiscal que não leve em consideração o ciclo econômico, tal como a atualmente utilizada no Brasil e baseada em metas fiscais anuais.

A sugestão para a superação deste problema em nenhum momento passa pelo abandono de uma política de equilíbrio fiscal de longo prazo. Duas propostas são apresentadas. A primeira assenta-se no "alongamento da periodicidade da meta de forma a abarcar o ciclo econômico". A segunda, considerada mais relevante para o debate:

Consiste em estabelecer um mecanismo institucional, com regras claras, que permita ao gasto público ser expansionista nos momentos de baixo crescimento e contracionista nos momentos de alto crescimento, preservando assim a continuidade de uma meta de superávit... Isso pode ser viável através de um fundo orçamentário com reservas de recursos públicos que, quando acionados, devem ter como finalidade específica o investimento público. Assim, haveria um aparato legal que permitiria a expansão do investimento público na baixa do ciclo econômico e obrigaria o Estado a poupar o excesso de arrecadação na alta do ciclo econômico (Biancarelli; Rossi, 2014, p. 33).

A defesa da construção de um mecanismo que obrigue o Estado a poupar em períodos de excesso de arrecadação é uma clara evidência da defesa por parte do social desenvolvimentismo de um equilíbrio fiscal no longo prazo, o que seria mais relevante que os resultados fiscais anuais. Não se pode afirmar, portanto, que exista uma complacência ou leniência com a persistência de desequilíbrios fiscais por parte do social desenvolvimentismo. 


\section{Conclusões}

Este artigo apresenta evidências que associações diretas entre "várias gerações de desenvolvimentistas" e a defesa de desequilíbrios fiscais como mecanismo de financiamento dos investimentos e a promoção do desenvolvimento não podem ser sustentadas numa análise mais detalhada do tema. Dois equívocos são cometidos por este tipo de abordagem, a la Franco (1996, 2004 e 2005). O primeiro é que não promove a necessária separação entre a produção intelectual dos desenvolvimentistas e a evolução histórica da política econômica nacional. $\mathrm{O}$ segundo é trabalhar o pensamento desenvolvimentista como um bloco homogêneo, desconsiderando as importantes distinções existentes entre os autores que colaboraram para a formação das diversas correntes deste pensamento.

Vale uma nota sobre a relação entre a evolução do pensamento econômico e da política econômica. É inegável que o pensamento desenvolvimentista foi relevante na elaboração de um conjunto de políticas econômicas durante o período do "ciclo ideológico do desenvolvimentismo", especialmente entre 1945-1964. No entanto, há que se chamar atenção para as significativas diferenças existentes entre o plano das ideias e o da execução das políticas econômicas.

A revisão dos trabalhos acadêmicos de Simonsen, Campos e Furtado permite concluir que é equivocada a associação direta entre as proposições dos autores para o financiamento dos investimentos industriais e, por exemplo, o uso de déficit público no financiamento dos investimentos durante o governo JK. O plano das ideias e o da execução da política econômica, ainda que mutuamente influenciados, precisam ser analisados em planos distintos (Fonseca, 2004) o que, de acordo a pesquisa realizada, não se apresenta na tese da leniência fiscal.

É importante chamar atenção também para a inadequação desta tese nas correntes contemporâneas do desenvolvimentismo. Tanto o novo quanto o social desenvolvimentismos não podem ser acusados de serem defensores de desequilíbrios fiscais crônicos como mecanismo de financiamento do desenvolvimento. No caso do primeiro, a crítica ao pensamento convencional concentra-se na inadequação do tratamento da questão fiscal a partir exclusivamente do comportamento dos gastos primários e na não observação dos efeitos das políticas monetária e cambial sobre o resultado fiscal.

No caso do social desenvolvimentismo, a questão fiscal deve ser compreendida de uma perspectiva mais ampla, já que para esta corrente o Estado deve desempenhar um papel de liderança no processo de desenvolvimento. Ainda assim, a proposta de metas fiscais flexíveis defende a necessidade de buscar uma trajetória de equilíbrio fiscal de longo prazo.

Por fim há que se ressaltar que a recuperação desta discussão tem também uma finalidade pedagógica, no sentido atribuído por Blaug (2001). Trabalhos como 
o de Franco ajudam a disseminar entre as novas gerações de economistas préconceitos, como a leniência fiscal dos expoentes intelectuais desenvolvimentistas e das novas gerações de desenvolvimentistas. Separam-se assim os "responsáveis" economistas ortodoxos da "irresponsabilidade" desenvolvimentista numa evidente estratégia de desqualificação do debate, como se as discussões econômicas pudessem ser binariamente separadas entre a "boa e má teoria econômica". Infelizmente para Franco e seus defensores a teoria e a realidade econômicas são substancialmente mais complexas.

\section{Referências bibliográficas}

BASTOS, P. P. Z. Ortodoxia e heterodoxia antes e durante a Era Vargas: contribuições para uma economia política da gestão macroeconômica dos anos 1930 . Economia Anpec (Selecta), v. 9, n. 4, dez. 2008.

BASTOS, P. P. Z. A economia política do novo-desenvolvimentismo e do social desenvolvimentismo. Economia e Sociedade, Campinas, v. 21, Número Especial, p. 779-810, dez. 2012.

BIANCARELLI, A.; ROSSI, P. A política macroeconômica e uma estratégia socialdesenvolvimentista. Revista Brasileira de Planejamento e Orçamento, Brasília, v. 4, n. 1, p. 21-38, 2014.

BIELSCHOWSKY, R. Pensamento econômico brasileiro: o ciclo ideológico do desenvolvimentismo. Rio de Janeiro: Ipea/Inpes, 1988. (Série PNPE, n. 19).

BIELSCHOWSKY, R. Estratégia de desenvolvimento e as três frentes de expansão no Brasil: um desenho conceitual. Economia e Sociedade, Campinas, v. 21, Número Especial, p. 729-747, dez. 2012.

BLAUG, M. No history of ideas, please, we're economists. The Journal of Economic Perspectives, v. 15, n. 1, p. 145-164, Winter 2001.

BOIANOVSKY, M. Celso Furtado and the structuralist-Monetarist debate on economic stabilization in Latin America. History of Political Economy, v. 44, n. 2, 2012.

BRESSER-PEREIRA, L. C. O novo desenvolvimentismo e a ortodoxia convencional. São Paulo em Perspectiva, v. 20, n. 3, p. 5-24, 2006.

BRESSER-PEREIRA, L. C. Globalization and competition: why some emergent countries succeed while others fall behind. Cambridge University Press, 2010.

BRESSER-PEREIRA, L. C.; GALA, P. O novo desenvolvimentismo e apontamentos para uma macroeconomia estruturalista do desenvolvimento. In: OREIRO, J. L.; DE PAULA, L. F.; BASÍlLIO, F (Org.). Macroeconomia do 
desenvolvimento: ensaios sobre restrição externa, financiamento e política macroeconômica. Recife: Editora Universitária UFPE, 2012.

BRESSER-PEREIRA, L. C.; NAKANO, Y. Crescimento econômico com poupança externa? Revista de Economia Política, v. 22, n. 2, p. 3-27, 2003.

CAMPOS, R. A crise econômica brasileira. Digesto Econômico, São Paulo, nov. 1953.

CAMPOS, R. Economia, planejamento e nacionalismo. Rio de Janeiro: APEC, 1963.

CAMPOS, R. Reflection on Latin American Development. Austin: Texas University Press, 1967.

CAMPOS, R. A lanterna na popa: memórias. 2. ed. Rio de Janeiro: Top Books, 1994.

CARNEIRO, R. M. Velhos e novos desenvolvimentismo. Economia \& Sociedade, Campinas, v. 21, Número Especial, p. 749-778, dez. 2012

CARONE, E. Roberto C Simonsen e sua obra. Revista de Administração de Empresas, Rio de Janeiro, v. 11, n. 4, p. 23-28, out./dez. 1971.

COELHO, F. S.; GRANZIERA, R. G. Celso Furtado e a formação econômica do Brasil. Edição Comemorativa dos 50 anos de publicação (1959-2009). São Paulo: Ordem dos Economistas do Brasil (OEB) e Atlas, 2009.

CURI, L. F. B.; CUNHA, A. M. Redimensionando a contribuição de Roberto Simonsen à controvérsia do planejamento (1944-45): pioneirismo e sintonia. In: ENCONTRO DA ASSOCIAÇÃO NACIONAL DE PÓS-GRADUAÇÃO EM ECONOMIA (Anpec), 39, Foz do Iguaçu, PR, 2011.

CURADO, M. L. Industrialização e Desenvolvimento: uma análise do pensamento econômico brasileiro. Economia e Sociedade, Campinas, v. 22, n. 3 (49), dez. 2013. CURADO, M.; CAVALIERI, M. A. R. Uma crítica à interpretação inflacionista do desenvolvimentismo. Economia e Sociedade, Campinas, v. 24, n. 1 (53), p. 57-86, abr. 2015.

FERRARI, F. F.; PAULA, L.F. Avaliação do regime cambial brasileiro pós-1999: análises crítica e propositiva. In: OREIRO, J. L.; DE PAULA, L. F.; BASÍLIO, F (Org.). Macroeconomia do desenvolvimento: ensaios sobre restrição externa, financiamento e política macroeconômica. Recife: Editora Universitária UFPE, 2012.

FONSECA, P. C. D. As origens e as vertentes formadoras do pensamento cepalino. Revista Brasileira de Economia, Rio de Janeiro, v. 54, n. 3, jul./set. 2000. 
FONSECA, P. C. D. Gênese e precursores do desenvolvimentismo no Brasil. Pesquisa \& Debate, v. 15, n. 2 (26), 2004.

FONSECA, P. C. D. O mito do populismo econômico de Vargas. Revista de Economia Política, São Paulo, v. 31, n. 1 (121), jan./mar. 2011.

FONSECA, P. C. D.; BASTOS, P. P. Z. (Org.) A era Vargas: desenvolvimentismo, economia e sociedade. São Paulo: Editora Unesp, 2011.

FURTADO, C. Características gerais da economia brasileira. Revista Brasileira de Economia, v. 4, p. 7-37, 1950.

FURTADO, C. Formação de capital e desenvolvimento econômico. Revista Brasileira de Economia, 1952.

FURTADO, C. The external disequilibrium in the underdeveloped economies. Indian Journal of Economics, v. 38, p. 403-410, 1958.

FURTADO, C. [1959]. Formação econômica do Brasil. Rio de Janeiro: Companhia Editora Nacional, 1968.

FURTADO, C. Desenvolvimento e subdesenvolvimento. Rio de Janeiro: Fundo de Cultura, 1961.

FURTADO, C. Panel: fiscal and financial policy. In: BAER, W.; KERSTENETZKY, I. (Org.). Inflation and growth in Latin America. Homewood, 1964, p. 496-499.

FURTADO, C. Análise do "modelo" brasileiro. 2. ed. Rio de Janeiro, 1972. (Coleção: Perspectivas do Homem, v. 92. Série Economia).

FURTADO, C. A fantasia organizada. Rio de Janeiro: Paz e Terra, 1985.

FRANCO, G. H. B. O desafio brasileiro: ensaios sobre desenvolvimento, globalização e moeda. Editora 34, 1996.

FRANCO, G. H. B. Auge e declínio do inflacionismo no Brasil. Rio de Janeiro: PUC. Departamento de Economia, 2004. (Texto para Discussão, n. 487).

FRANCO, G. H. B. Auge e declínio do inflacionismo no Brasil. In: GIAMBIAGI, G.; VILlELA, A.; CASTRO, L. B.; HERMANN, J. (Org.). Economia brasileira contemporânea (1945-2004). Rio de Janeiro: Campus Elsevier, 2005.

GODOI, B. B. C. A influência de Roberto Campos na economia brasileira (19452001). Dissertação (Mestrado)-Programa de Pós-Graduação em História Econômica da Universidade de São Paulo (USP), 2007.

KALDOR, N. Causes of the slow rate of economic growth of the United Kingdom: an inaugural lecture. Cambridge: Cambridge University Press, 1966 
MAZA, F. O idealismo prático de Roberto Simonsen: ciência, tecnologia e indústria na formação da nação. Tese (Doutorado)-Programa de Pós-Graduação em História Social. Universidade de São Paulo, 2002

MOLlO, M. R. L.; FONSECA, P. C. D. Desenvolvimentismo e novodesenvolvimentismo: raízes teóricas e precisões conceituais. Revista de Economia Política, v. 33, n. 2 (131), p. 222-239, abr.jun. 2013.

OREIRO, J. L.; PAULA, L. F. O novo desenvolvimentismo e a agenda de reformas macroeconômicas para o crescimento sustentado com estabilidade de preços e equidade social. In: OREIRO, J. L.; DE PAULA, L. F.; BASÍlLIO, F. (Org.). Macroeconomia do desenvolvimento: ensaios sobre restrição externa, financiamento e política macroeconômica. Recife: Editora Universitária UFPE, 2012.

PREBISCH, R. The economic development of Latin America and its principal problems. Economic Commission for Latin America, 1949. (Document ECN 12.89).

SIMONSEN, R. Sugestões para uma política econômica pan-americana: problemas do desenvolvimento econômico latino-americano. Rio de Janeiro: Confederação Nacional da Indústria, 1947a.

SIMONSEN, R. O Plano Marshall e suas prováveis repercussões econômicas na América Latina. Rio de Janeiro: s/ editora, 1947b.

SIMONSEN, R. A situação econômica da América Latina e suas possibilidades em face do Plano Marshall (Contribuição para conferência interamericana de Bogotá). São Paulo: Departamento de Economia Industrial, 1948.

SIMONSEN, R. O Plano Marshall e um novo critério nas relações internacionais. Rio de Janeiro: s/ editora, 1949.

SIMONSEN, R. A planificação da economia brasileira. In: SIMONSEN, R.; GUDIN, E.; VON DOELLINGER, C. A controvérsia do planejamento na economia brasileira. 3. ed. Brasília: Ipea, 2010a.

SIMONSEN, R. O planejamento da economia brasileira - Réplica ao Sr. Eugênio Gudin. In: SIMONSEN, R.; GUDIN, E.; VON DOELLINGER, C. A controvérsia do planejamento na economia brasileira. 3. ed. Brasília: Ipea, 2010b.

SZMRECSÁNYI, T. Pensamento econômico no Brasil contemporâneo: Celso Furtado. Estudos Avançados, São Paulo, v. 15, n. 43, set./dec. 2001.

TEIXEIRA, A., MARINGONI, G.; GENTIL, L. Roberto Simonsen e Eugênio Gudin: desenvolvimento, o debate pioneiro (1944-45). Brasília: Instituto de Pesquisa Econômica Aplicada, 2010.

VIANNA, S. B.; VILELLA, A. O pós-guerra. In: GIAMBIAGI, F.; VILLELA, A,; CASTRO, L. B.; HERMANN, J. (Org.). Economia brasileira contemporânea [1945-2010]. 2. ed. Editora Campus, 2011. 